\title{
Structural stigma, sex work and HIV: contradictions and lessons learnt from a community-led structural intervention in southern India
}

\author{
Monica Rao Biradavolu, ${ }^{1}$ Kim M Blankenship, ${ }^{1}$ Asima Jena, ${ }^{2}$ Nimesh Dhungana ${ }^{3}$
}

'Department of Sociology, Center on Health Risk and Society, American University, Washington, DC, USA ${ }^{2}$ Center for Studies in Society and Development, School of Social Sciences, Central University, Gandhinagar, Gujarat, India

${ }^{3}$ Center on Health Risk and Society, American University, Washington, DC, USA

Correspondence to Dr Monica Rao Biradavolu, Department of Sociology, Battelle-Tompkins Hall, American University, 4400 Massachusetts Avenue NW Washington, DC 20016-8072, USA; monica.biradavolu@ american.edu

Accepted 13 April 2012 Published Online First 15 June 2012

\section{(2) UNLOCKE}

This paper is freely available online under the BMJ Journals unlocked scheme, see http:// jech.bmi.com/site/about/ unlocked.xhtml

\begin{abstract}
Background Recent theorisation has pushed stigma research in new directions, arguing for a need to challenge the unequal power relations that impact groups most at risk for HIV-related stigma rather than locate stigma in the individual. Such a conceptualisation resonates with the growing emphasis on structural interventions for HIV prevention that attempt to alter the social context of risk.

Methods The paper predominantly relies on longitudinal interviews conducted three times over a 2-year period with sex workers with varying degrees of involvement with the non-governmental organisation (NGO) and community-based organisation.

Results Recognising that stigma is socially constructed and structurally reproduced, the NGO helped mobilise marginalised and hitherto scattered female sex workers to form community-based organisations to challenge their disadvantaged status in society. The authors show how stigma alleviation strategies presented a contradiction: emboldening one group of female sex workers to self-identify as sex workers while making others reluctant to access the intervention-run clinic. Conclusion The paper builds on a growing body of research that acknowledges the struggles in implementing structural interventions, particularly for NGOs working in regions with a diverse population of sex workers with varying needs. The authors argue that intervention goals of reducing stigma and increasing the use of sexually transmitted infection services do not have to conflict and, in fact, must go hand-in-hand for an implementation to be considered a structural intervention
\end{abstract}

\section{INTRODUCTION}

Challenging stigma is necessary for HIV prevention $^{1} 2$ but doing so is complicated when HIV doubly stigmatises already marginalised groups such as female sex workers (FSWs). ${ }^{3}$ With increasing emphasis on structural interventions to alter the social context of risk, ${ }^{45}$ focus has shifted to addressing structural stigma ${ }^{6}$ rather than locating stigma in the individual and researching dyadic 'face-to-face' interactions. ${ }^{7}$ Recent theorisation incorporates notions of power to analyse how stigma is socially constructed, institutionalised and structurally reproduced. ${ }^{8} 9$ Contextspecific research that includes voices of the stigmatised is emphasised, ${ }^{10}$ and researchers are urged to understand stigma relationally as part of a social world inhabited not just by the stigmatised but also by those who exert the power to label and discriminate. ${ }^{11}$ Strategies to alleviate stigma for
HIV-affected populations can take different forms When stigma is conceptualised as reflecting unequal power relations, intervention strategies that produce social transformations through mobilisation of disadvantaged communities are favoured over behaviour change models that improve the coping skills of the stigmatised or increase the tolerance and empathy of those who stigmatise. ${ }^{12}$

This paper uses longitudinal data of a community-led structural intervention (CLSI) for HIV prevention among FSWs in India, whose goals included addressing the fundamental causes of stigma. Our data show how the intervention mobilised FSWs to form community-based organisations (CBOs) to question the dominant ideology that discriminated against sex workers. Doing so presented a contradiction: a group of FSWs who were willing to boldly self-identify as sex workers and advocate on behalf of their peers even as another group of 'secret' sex workers became reluctant to attend the intervention-run clinic.

While there is research on strategies sex workers use to reconstitute stigmatised identities, particularly in South Asian settings, ${ }^{13}{ }^{14}$ there is scant evidence that examines the consequences of doing so in the context of HIV implementation activities. We describe the strategies employed to address stigma within the larger context of the intervention's mobilisation efforts and answer the call to conduct strategic and policy-oriented research to 'describe the combination of programme elements' that challenge HIV-related stigma and the 'likely outcomes of specific kinds of programme implementation' (Parker and Aggleton 2003: 2012). In addition, the paper also builds on a growing body of work that provides nuanced accounts of strategies involved in implementing structural interventions. Such accounts have helped clarify concepts, ${ }_{15}^{15}$ acknowledged the struggles involved in implementation ${ }^{17} 18$ and ensured that implementation goals are realistic. ${ }^{19} 20$

We begin by describing the key elements of the intervention and the sex work context within which the implementation activities took place. We then examine the inherent tensions in challenging FSWs' disadvantaged status in society and conclude by discussing how the lessons learnt here can inform future HIV programming activities with FSWs.

\section{CARE-SAKSHAM'S INTERVENTION IN RAJAHMUNDRY: 2004-2009}

Care-Saksham, a local branch of the international NGO Care, was one of 130 interventions funded in 
six high-prevalence states by the Bill \& Melinda Gates Foundation's Avahan India AIDS Initiative. It began operations in Rajahmundry in October 2004. Rajahmundry is a semiurban town of 400000 in the largely rural, agriculturally rich and economically prosperous East Godavari district in Andhra Pradesh state, India. East Godavari, of which Rajahmundry is the commercial hub, is among the districts most severely affected by HIV, particularly among its FSW population. ${ }^{21}$

Care-Saksham's mandate was to implement a CLSI for HIV prevention with FSWs and emulate the Sonagachi Project, which began in Kolkata's largest red-light district, with an estimated 5000 FSWs and is hailed as a successful model. ${ }^{22}$ The Sonagachi Project has been responsible for increasing condom use among FSWs and lowering rates of sexually transmitted infections (STIs) and HIV. The project used a multi-faceted approach to HIV prevention, improving individual skills and competencies, and aimed to change the larger social environment in which sex work took place. ${ }^{23}$ However, there are at least two critical differences between the Sonagachi and Rajahmundry interventions. First, Sonagachi began as an educational intervention on HIV and developed over time into a community empowerment project. By contrast, the Rajahmundry intervention combined, from the very start, three elements considered integral to implementing CLSI: control over access to services (through condom distribution and STI treatment); community mobilisation (through peer education, community building and formation of sex worker CBOs); and creation of an enabling environment (advocating with police, organising public events to challenge sex worker stigma and media advocacy to encourage positive portrayals of sex work). Second, Sonagachi explicitly targeted brothels in a red-light district in a large metropolitan city. ${ }^{24}$ Care-Saksham's operational area comprised eight 'mandals', subdistrict administrative units, where FSWs were scattered in both urban and rural settings, soliciting in brothels, homes, agricultural fields and lodges, on streets and highways and in various combinations of these forms. ${ }^{25}$ FSWs also categorised themselves as being 'public' or secret. These are not mutually exclusive categories, since a woman may be visible working along highways, streets or known public brothels in town while her sex work identity remains secret in her village. The implication, nevertheless, is that a self-identified secret FSW takes greater precautions in keeping her sex work identity hidden. ${ }^{26}$

Care-Saksham began by identifying 32 social change agents (SCAs) across the spectrum of urban and rural locations and trained them to be peer educators and community organisers. The number of trained SCAs rose to 70 by the end of the first year. Each SCA worked with 10 FSWs to cover the 700 FSWs (the most recent round of mapping has enumerated 2,890 FSWs). The SCAs engaged in distributing free condoms and bringing peers to the intervention-run STI clinic and drop-in centres. Care-Saksham's goal was to eventually hand over control of the intervention to a sex worker $\mathrm{CBO}$, as had been accomplished in Sonagachi through a sex workers' union, Durbar Mahila Samanwaya Committee. Therefore, 5 months after beginning operations, on International Sex Workers' Day on 3 March 2005, Care-Saksham helped set up a sex workers' $\mathrm{CBO}$, Nari-Saksham. The core committee of Nari-Saksham was formed on the same day, by secret ballot. Each SCA present chose three of her peers: the three most popular comprised the core committee and the one with the most votes became the core committee president.

Since FSWs were geographically dispersed, Care-Saksham also initiated several smaller local CBOs. Brothel-based sex workers in the village of Dowleswaram on the outskirts of Rajahmundry town were the first to form their own local CBO; secret FSWs who operated out of rural areas, far from Care-Saksham's office, were the slowest to collectivise in this manner. Nevertheless, by 2008, there were 12 local-area CBOs, with Nari-Saksham as the umbrella organisation. For organisational integration, the President and Vice-President of every local CBO were inducted into the core committee of Nari-Saksham. Additionally, three other committees comprising FSWs were formed. The Crisis Intervention Team was a $24 \mathrm{~h}$ emergency response team, primarily dealing with policing issues; Arogya Brindam was the health committee to oversee clinic and condom distribution activities; and the drop-in centre (DIC) committee was to ensure the smooth functioning of the drop-in centres. Together, these three committees helped to ensure key intervention activities were 'community-led'. To integrate the specialised committees into Nari-Saksham, one member each was inducted into the core committee of Nari-Saksham.

Care-Saksham ran the intervention from 2004 to 2009. In 2010, the Gates Foundation's Avahan programme began phasing out and transferring the administration of interventions to the Government of India. Control over the Rajahmundry intervention has changed hands twice since 2009, but the promised handover to the $\mathrm{CBO}$ has not yet occurred. Nari-Saksham has been evaluated as part of the government takeover and the $\mathrm{CBO}$ presents a dichotomy: it is recognised for its success in creating a group of empowered FSWs who can fight for their rights; on numerical indicators of regular clinic attendance, however, the $\mathrm{CBO}$ is rated below average. An understanding of CareSaksham's strategies to challenge sex worker stigma provides insights into the tension between achieving these different intervention goals.

\section{METHODS}

Data are drawn from a multi-methods research study-Project Parivartan-which aims to analyse the implementation and impact of the intervention in Rajahmundry. From February 2005 to June 2007, Project Parivartan had a field office in Rajahmundry, comprising four ethnographers fluent in English and Telugu including two of the authors of this paper. The fourperson team gathered all the qualitative data. Project Parivartan's research began at the same time that Care-Saksham started operations but the research project worked independently of both the non-governmental organisation (NGO) and $\mathrm{CBO}$ - it has no intervention implementation responsibilities.

The analysis in this paper predominantly relies upon semistructured longitudinal interviews conducted thrice between October 2005 and March 2007, with sex workers with varying degrees of involvement with Nari-Saksham. The levels of involvement were conceptualised after discussions with NGO staff. The highest degree of involvement was among SCAs who also held leadership positions as core committee members of Nari-Saksham. The next highest were SCAs and members of Nari-Saksham who were not on the core committee. The third level were members of local-area $\mathrm{CBO}$ s but were not SCAs. Their contact with the intervention was through their association with SCAs and through local-area CBO activities. Finally, the respondents at the lowest rung had the least involvement as they were neither SCAs nor members of local-area CBOs. Over the course of the three rounds of interviews, the respondents moved in and out of these levels. Round 1 included 22 respondents; rounds 2 and 3 included 17 and 16, respectively. The attrition in follow-up rounds was among those with the least level of involvement to begin with. Each interview lasted up to $2 \mathrm{~h}$, were conducted in the Parivartan office after taking 
informed consent, audio-recorded and transcribed from Telugu to English. The findings from each round of the longitudinal interviews were analysed and compiled into reports and shared as part of Parivartan's monthly feedback sessions with the NGO and $\mathrm{CBO}$.

It is instructive to point out that the guides developed for the longitudinal interviews relied heavily upon other qualitative data collected as part of the overall study. The near-daily observational data of Care-Saksham and Nari-Saksham activities generated questions in the longitudinal interviews that were tailored to specific ongoing events, activities, incidents, issues and concerns of the NGO and $\mathrm{CBO}$. Key insights from periodic, formal, semistructured interviews with Care-Saksham staff and key informants in the sex trade, including brokers, police, clients and intimate partners, were also incorporated into the longitudinal interview guides. Through observations and informal interviews at multiple sex work locations in the area, the research project also developed an understanding of the sex industry's embeddedness in the local economy. The vast data generated were compiled on a weekly basis at research meetings by the Rajahmundry team and shared with the US-based team. The weekly meeting minutes were compiled into monthly research reports. In addition, data were compiled into descriptive reports on topical areas, including one on CBOs, from which this paper draws.

From 2008 onwards, the research has involved periodic field visits for continued active engagement at the site. At the time of writing, we have conducted four follow-up visits, providing us with unique longitudinal data over 6 years. Ethical approval was obtained at the Institutional Review Boards of Yale University, Duke University, American University and through YRG Care, a research institution in India.

\section{FINDINGS}

\section{CBO formation as a strategy to challenge sex worker stigma}

For Care-Saksham, forming Nari-Saksham, local CBOs and specialised committees were a necessary CLSI strategy to: build collective identity and cohesion for a scattered FSW population; formalise FSWs' representation in the project management structure; build alliances and partnerships with other organisations; build ownership over the project for the eventual handover to the 'community'; allow FSWs to gather publicly under the CBO's banner; and be a community asset to help FSWs access and demand social services and civic benefits that all citizens enjoy. The formation of the smaller local $\mathrm{CBO}$ s created a network of organisations so that $\mathrm{CBO}$ s across mandals, districts and states would get the size and strength to negotiate with powerful state institutions. CBO formation was a step towards HIV prevention because an empowered FSW community would address their vulnerabilities, including to HIV. The strategy had been shown to work in Sonagachi, which NariSaksham was attempting to emulate.

CBOs were also instrumental in addressing sex worker stigma, an issue oftentimes ignored by implementers when discussing challenges to implementation. FSWs could now identify with an organisation meant specifically for their occupational group. Care-Saksham's Project Manager articulated her reasons for why challenging stigma was important and what she wanted NariSaksham to be able to achieve:

For me, the main concern is FSWs' status in society. Many NGOs form SHGs [Self-Help Groups] for FSWs or show FSWs how to access government programs. These are important. But the women in those programs don't come out. They say they are part of some women's groups. The FSWs get benefits but these achievements are not enough. Nobody knows they are sex workers. The women continue to feel shame, feel afraid, how can this be empowerment? They are only happy when they are in the NGO office, not outside. For me, if there are ten women who can articulate their problems, or are depressed about being in the position they are in, and know that their situation has to be changed, that is more important. That is structural change. In that sense, our women [SCAs] articulate their rights. I feel if we give them the funds we [the NGOs] get, they can do what we do. That requires giving them training, which is hard but not the most difficult. But developing their self-identity, including dealing with their internal stigma... THAT is the main challenge (Care-Saksham's Project Manager, November 2005).

Establishing Nari-Saksham as a fully-functioning CBO required considerable time, effort and input on the part of Care-Saksham staff to train the largely non-literate $\mathrm{CBO}$ members in organisational management. Over time, members learnt disciplinary norms, agenda creation, documentation and implementing decisions. Through regular elections and rotation of leaders, they participated in democratic governance. They received training in monitoring activities, performance evaluation and public speaking. SCAs participated in, took decisions on and felt ownership of implementation activities and developed confidence in their abilities to run an organisation. Our longitudinal interviews show that in round 1 (conducted 6 months after the formation of the CBO), the majority of FSWs (17 out of 22) worried about Care-Saksham leaving Rajahmundry, expressing concerns about the loss of financial support, but also a loss of power as Care-Saksham had the ability to influence police and other officials. Sex workers were not comfortable taking over these activities on their own yet. By round 3 (2 years after CBO formation), the situation was reversed: the majority of the respondents (15 out of 17) were confident that Nari-Saksham was capable of taking over from Care-Saksham. When asked how the $\mathrm{CBO}$ would prepare reports, use computers or manage finances, the respondents said that educated SCAs would be given more specific training to take over such activities.

Further emulating Sonagachi, the creation and strengthening of the CBO also allowed Nari-Saksham to conduct police and media advocacy and organise public events where the $\mathrm{CBO}$ members visibly identified themselves as sex workers. These events had a twofold purpose: to create an 'enabling environment' for FSWs while also challenging sex worker stigma. Findings from how Nari-Saksham mobilised to question and change policing practices and organised a large-scale public event to challenge sex work stigma have been reported elsewhere. ${ }^{17} 27$

The quotes below-one by an SCA and the other by a nonSCA-from longitudinal interviews conducted more than 2 years after the $\mathrm{CBO}$ was set up highlight the changes that the $\mathrm{CBO}$ brought in the lives of sex workers.

We used to think that sex work is bad work and we are doing something wrong. We never bothered about other sex workers. Once, a sex worker who I knew took a party [client] to a lodge. The police came there. I was there but I hid in the bathroom. The police took her and wrote in bold letters on a slate that she is a prostitute and hung it in her neck and made her walk. They threatened that she should not be seen again. We saw the problem but could not do anything. Our sympathy was with her but we could not approach her as we were not intelligent then and we were also afraid. Now we have our CBO. I can say boldly I am from Nari-Saksham, a sex workers' organisation. We do not let the police harass sex workers like that (street sex worker, core committee member, SCA).

They [SCAs] are working hard for our welfare. They are trying to decrease humiliation about sex work and create respect for us in 
public. When police or rowdies come, they help us. There is no need to go to the shop to buy condoms because they provide them free. They take us to the clinic. Whenever there is a meeting [organised by Care-Saksham], they inform us. They have also promised to provide us with housing plots, ration cards and finance to start some trade. They will do it for us. It is true (highway sex worker, non-SCA).

However, even as there was greater collectivisation among sex workers and greater courage to stand up to powerful forces such as the police, one issue persisted: SCAs' poor performance in bringing peers for regular check-ups at the clinic.

\section{Contradictions of challenging sex worker stigma}

The SCAs' bold self-identification as sex workers helped in one intervention activity-challenging stigma-and yet contributed to undermining another intervention goal-their ability to convince all peers to seek services at the Care-Saksham-run clinic. In rounds 2 and 3 of the longitudinal interviews, the respondents who were SCAs revealed that stigma prevented women from accessing the intervention-run clinic, including the stigma of testing HIV+, stigma surrounding the clinic in particular (being seen at an 'HIV clinic') as well as stigma of sex work (the discomfort of being seen in the company of SCAs who make no effort to hide their sex worker status). Specifically, SCAs from rural areas of the district whose peers were homebased emphasised the difficulty of convincing the secret sex workers to access services at the Care-Saksham clinic.

\section{The women in my village think that the Care clinic is only for business girls. Family ones don't go there (home-based sex worker, SCA, non-core committee member)}

Another SCA, who held a leadership position in the core committee, was outspoken about her sex worker identity and had spoken fearlessly in public on behalf of Nari-Saksham, concurred. While she conducted her business 'publicly' outside cinemas in the town centre, she was responsible as an SCA for the secret sex workers in her village on the outskirts of town. She emphasised that women in her village were interested to receive services offered in the Care-Saksham clinic but were fearful of being stigmatised by associating with a public sex worker. The SCA and the sex worker devised ways to circumvent the problem:

I walk from my home to the bus stop. One of the sex workers I work with lives next door. She wants to go to the clinic but she does not want to be seen walking with me as I am public and she is secret. So she comes to the bus stop separately. And then we go together to Care-Saksham clinic (street sex worker, core committee member and SCA).

SCAs suggested that the intervention treat all women at the clinic, not just FSWs. This strategy was suggested because many women, including non-sex workers, were interested in accessing services but were reluctant to do so because of the clinic's association with sex workers.

Care-Saksham wants only sex workers. They should treat all, even if she is not a sex worker. What will such people [non-sex workers] do in society? They too should be treated and given medicines. There's a woman who had STIs and she knew I took girls to the clinic with such problems. She asked me to take her. How could I say I wouldn't? So I brought her to the clinic and she got treated. But she is not a sex worker (Street sex worker, SCA).

On the one hand, treating all women with STIs regardless of their sex worker status reduced stigma experienced by the secret FSWs, whose main concern was not to be distinguished from non-sex workers; on the other hand, Care-Saksham's mandate was to implement an intervention through mobilising the community of FSWs. These were some of the dilemmas the intervention had to negotiate to implement a structural intervention that could meet the needs of a diverse sex worker population.

\section{DISCUSSION AND CONCLUSION}

Care-Saksham's approach to challenge sex worker stigma was 'multi-faceted, multi-level and addressed the fundamental causes of stigma,' aspects that theorists consider critical to how the problem needs to be addressed (Link and Phelan 2001: 381 ${ }^{8}$ ). By tackling both internalised stigma and stigma attributed by outsiders, Care-Saksham launched a multi-level effort. Through mobilisation and advocacy, Nari-Saksham members questioned the stigmatising views of powerful groups and the ideology underlying such attitudes. By forming a network of CBOs and interacting with important stakeholders, the empowered sex workers tried to change the circumstances that made them powerless in the first place, thereby limiting the power of those whose cognitions were dominant. However, self-identifying as sex workers, while mobilising and empowering some, distanced and silenced other groups of sex workers. Care-Saksham had to acknowledge the diversity of FSWs in the area and delicately balance encouraging sex workers willing to come forward boldly while at the same time protecting those who were reluctant.

What this paper has demonstrated is that in short order NariSaksham members formed CBOs and created a community of a hitherto scattered sex worker population, while similar efforts have proven unsuccessful among FSWs in other parts of India. ${ }^{28}$ It can be argued that Care-Saksham's stigma reduction strategies were an important tool to mobilise sex workers in the first place.

\section{What is already known on this subject}

Structural interventions that go beyond altering individual behaviours and instead aim to mobilise disadvantaged communities to change the social context of risk are considered essential to HIV prevention. It is recognised that a part of the toolkit of strategies for implementing structural interventions includes challenging structural stigma, that is, the unequal power relations that stigmatise groups most at risk of HIV. However, doing so is complicated when HIV stigma further burdens already marginalised groups such as female sex workers.

\section{What this study adds}

While there is research on strategies sex workers use to reconstitute stigmatised identities, there is scant evidence that examines the consequences of doing so in the context of HIV implementation activities. The study highlights the inherent contradictions of challenging structural stigma in a region with a diverse group of sex workers. Efforts at alleviating sex worker stigma emboldened one group of female sex workers to selfidentify as sex workers while making others reluctant to access the intervention-run clinic. The data presented add to a growing body of work that acknowledges the struggles involved in implementing structural interventions, thereby ensuring that implementation goals are realistic. 


\section{Policy implications}

It can be argued that the stigma reduction strategies were an important tool to mobilise sex workers in the first place. Yet, as a public health intervention, the non-governmental organisation had to demonstrate success in bringing female sex workers to the sexually transmitted infection (STI) clinics. Clinic attendance is used in evaluation data as a measure of 'success' whereas stigma reduction is more challenging to measure quantitatively nor is it typically seen as an appropriate way of measuring the success of a health intervention. Intervention goals of reducing stigma and increasing the use of STI services do not have to conflict and, in fact, must go hand-in-hand for an implementation to be considered a structural intervention. Since reducing stigma around sex work is a long-term process, especially for implementers working with a diverse sex worker population, it is important to allow interventions time to unfold. Community mobilisation (through the formation of community-based organisations and advocacy) and targeted interventions (STI and HIV reduction through clinic visits and condom distribution) should not be considered mutually exclusive goals.

Yet, as a public health intervention, the NGO had to demonstrate success in bringing FSWs to the STI clinics. Clinic attendance is used in evaluation data as a measure of 'success' whereas stigma reduction is more challenging to measure quantitatively nor is it typically seen as an appropriate way of measuring the success of a health intervention. Intervention goals of reducing stigma and increasing the use of STI services do not have to conflict and, in fact, must go hand-in-hand for an implementation to be considered a structural intervention. Since reducing stigma around sex work is a long-term process, especially for implementers working with a diverse sex worker population, it is important to allow interventions time to unfold. Community mobilisation (through the formation of CBOs and advocacy) and targeted interventions (STI and HIV reduction through clinic visits, condom distribution, etc) should not be considered mutually exclusive goals. In addition, recognising the diversity of the FSW population in the region, including rural, secret FSWs, interventions must improve the outreach efforts to these hidden, hard-to-reach populations.

Acknowledgements The authors wish to Care-Saksham and Nari-Saksham for their participation in the research study.

Contributors MRB contributed to the acquisition, analysis and interpretation of data; drafting the article and revising based on reviewer comments. KMB contributed to the conception, design, analysis and interpretation of data and revised the article for important intellectual content. AJ contributed to the acquisition, analysis and interpretation of data and revised the article for important intellectual content. ND contributed to the analysis and interpretation of data and revised the article for important intellectual content.

Funding Support for this research was provided by the Bill \& Melinda Gates Foundation's Avahan India AIDS Initiative through Grant No. 30183. The views expressed herein are those of the authors and do not necessarily reflect the official policy or position of the Bill \& Melinda Gates Foundation and Avahan.

Competing interests None.

Patient consent There are no patients in this study. Consent was obtained from interview respondents.
Ethics approval The ethics approval was provided by Yale University, Duke University and American University (in the US) and YRG-Care (Chennai, India)

Provenance and peer review Commissioned; externally peer reviewed.

\section{REFERENCES}

1. Steward WT, Herek GM, Ramakrishna J, et al. HIV-related stigma: adapting a theoretical framework for use in India. Soc Sci Med 2008:67:1225-35.

2. Link BG, Phelan JC. Stigma and its public health implications. Lancet 2006;367:528-9

3. Herdt G. Stigma and the ethnographic study of HIV: problems and prospects. AIDS Behav 2001;5:141-9.

4. Blankenship KM, Friedman SR, Dworkin SL, et al. Structural interventions: concepts, challenges, and opportunities for research. J Urban Health 2006;83:59-72.

5. Parker RG, Easton D, Klein CH. Structural barriers and facilitators in HIV prevention: a review of international research. AIDS 2000;14(Suppl 1):S22-32.

6. Scrambler G. Sociology, social structure and health-related stigma. Psychol Health Med 2006:11:288-95.

7. Goffman E. Stigma: Notes on the Management of Spoiled Identity. New York: Prentice-Hall, 1963.

8. Link BG, Phelan JC. Conceptualizing stigma. Annu Rev Sociol 2001; 27:363-85.

9. Castro A, Farmer P. Understanding and addressing AIDS-related stigma: from anthropological theory to clinical practice in Haiti. Am J Public Health 2005; 95:53-8.

10. Keusch GT, Wilentz J, Kleinman A. Stigma and global health: developing a research agenda. Lancet 2006;367:525-7.

11. Yang LH, Kleinman A. 'Face' and the embodiment of stigma in China: the cases of schizophrenia and AIDS. Soc Sci Med 2008;67:398-408.

12. Parker R, Aggleton P. HIV and AIDS-related stigma and discrimination: a conceptual framework and implications for action. Soc Sci Med 2003;57:13-24.

13. Chowdhury R. "Outsiders" and identity reconstruction in the sex workers' movement in Bangladesh. Sociol Spectr 2006;26:335-57.

14. Cornish F. Challenging the stigma of sex work in India: material context and symbolic change. J Community App/ Soc Psychol 2006;16:462-71.

15. Auerbach JD, Parkhurst J0, Caceres CF. Addressing social drivers of HIV/AIDS for the long-term response: conceptual and methodological considerations. Glob Public Health 2011;6(Suppl 3):S293-309.

16. Evans C, Jana $\mathrm{S}$, Lambert $\mathrm{H}$. What makes a structural intervention? Reducing vulnerabilities to HIV in community settings, with particular reference to sex work. Glob Public Health 2010;5:449-61.

17. Blankenship KM, Biradavolu MR, Jena A, et al. Challenging the stigmatization of female sex workers through a community-led structural intervention: learning from a case study of a female sex worker intervention in Andhra Pradesh, India. AIDS Care 2010;22(Suppl 2):1629-36.

18. Dickson-Gomez J, Corbett AM, Bodnar G, et al. Resources and obstacles to developing and implementing a structural intervention to prevent HIV in San Salvador, El Salvador. Soc Sci Med 2010;70:351-9.

19. Cornish F, Ghosh R. The necessary contradictions of 'community-led' health promotion: a case study of HIV prevention in an Indian red light district. Soc Sci Med 2007; 64:496-507.

20. Evans C, Lambert H. Implementing community interventions for HIV prevention: insights from project ethnography. Soc Sci Med 2008;66:467-78.

21. National AIDS Control Organization, United Nations Children's Fund and United Nations Development Program. Concurrent Assessment of Link Worker Scheme in Andhra Pradesh. http://www.nacoonline.org/upload/Link Worker Scheme/ Evaluation Reports/2010/LWSassessment AP report revised.pdf laccessed 21 Aug 2011).

22. Pardasani MP. HIV prevention and sex workers: an international lesson in empowerment. Int J Soc Welf 2005;14:116-26.

23. Jana S, Basu I, Rotheram-Borus MJ, et al. The Sonagachi Project: a sustainable community intervention program. AIDS Educ Prev 2004;16:405-15.

24. Ghose T, Swendeman DT, George SM. The role of brothels in reducing HIV risk in Sonagachi, India. Qual health Res 2011;21:587-600.

25. Dandona R, Dandona L, Gutierrez JP, et al. High risk of HIV in non-brothel based female sex workers in India. BMC Public Health 2005. http://www.biomedcentral. com/1471-2458/5/87 (accessed 23 Aug 2011)

26. Buzdugan R, Halli SS, Cowan FM. The female sex work typology in India in the context of HIV/AIDS. Trop Med Int Health 2009;14:673-87.

27. Biradavolu MR, Burris S, George A, et al. Can sex workers regulate police? Learning from an HIV prevention project for sex workers in southern India. Soc Sci Med 2009;68:1541-7.

28. Asthana $\mathbf{S}$, Oostvogels R. Community participation in HIV prevention: problems and prospects for community-based strategies among female sex workers in Madras. Soc Sci Med 1996;43:133-48. 